\title{
ANALYSIS OF THE IMPACT OF UNSCHEDULED DOWNTIMES ON THEIR AVAILABILITY IN MACHINE OPERATIONS
}

doi:10.2478/mape-2018-0019

Date of submission of the article to the Editor: 03/2018 Date of acceptance of the article by the Editor: 05/2018
MAPE 2018, volume 1, issue 1, pp. 145-151

\section{Dr hab. inż. Jarosław Brodny}

Silesian University of Technology, Poland

\begin{abstract}
Unscheduled downtimes in machine operation are one of the main reasons behind their low availability. Such downtimes are caused by miscellaneous factors and remain difficult to identify in a number of cases. This particularly refers to enterprises that conduct their activities in changing external conditions, such as hard coal mines, where exploitation is carried out in extremely complicated, changeable and dangerous conditions. The process of coal production makes use of various machines that must be adapted to these conditions. The specificity of the working environment makes it necessary for these machines to exhibit high reliability, readiness and efficiency. These features, in turn, make the cost of the machines very high. It is therefore reasonable to make the best use of their capabilities, which translates into the effectiveness of the entire production process. The article concentrates on determining the availability of these machines. It has been assumed that availability is one of the fundamental parameters that define the effective utilisation of machines. The tests were conducted for a longwall shearer as well as an armoured face conveyor and a main haulage conveyor in one of the hard coal mines in Poland. Industrial automation systems were used to determine unscheduled downtimes in the operation of these machines, as well as their time structure and causes. The results obtained indicate that the number of unscheduled downtimes represents a serious problem in mining exploitation.
\end{abstract}

Keywords: mining production, unscheduled downtimes, mining machines, efficiency, availability.

\section{INTRODUCTION}

In a free and open market, all enterprises strive to achieve the best effects of their activities. To make it possible, they do their best to optimally utilise the technical, human and intellectual resources possessed. While creating a competitive advantage on the challenging market, it is crucial to take account of all the production-related aspects. This is also true of hard coal mining. This sector too is attaching increasing importance to the optimisation of the production process by analysing its particular stages and implementing changes with a view to achieving better results. The fragmented approach to this problem stems from the absence of adequate investment resources. For this reason, this sector is making increasingly extensive use of new technical solutions that have been successfully applied in other sectors of the economy. These include, for example, industrial automation systems that are available in mining machinery and whose results are not always used for improving the effectiveness of this sector. At present, virtually all the sectors of the economy are taking advantage of industrial automation systems, which support the production process and its management. Due to the specific working conditions, the machinery used in mining are exposed to a number of factors that are nonexistent in the establishments from other sectors. As a result, these conditions make it necessary to utilise all the capabilities in order to monitor their operating status. External factors, related to the fortuitous nature of environmental interactions (in this case, the rock mass, gases, temperature, etc.), make it impossible to fully predict the conditions in which these machines will be working (Stecuła et al., 2017a). This particularly refers to various types of hazards that occur during the process of underground exploitation. These hazards involve 
methane (Brodny and Tutak, 2016; Tutak, 2017a) and fire (Tutak and Brodny, 2017b; Tutak, 2017b) risks, which can significantly disrupt this process.

As a result, these machines must have considerably higher working coefficients and technical parameters than their counterparts operated on the ground. At the same time, in order to achieve the expected effects, the operation of the machines must proceed as scheduled. Any unscheduled downtimes and low effectiveness are difficult to accept. In order to assess the operating status of the machines, tests were conducted to determine the number of their unscheduled downtimes. The tests were carried out for selected machines within the automated longwall system that is responsible for direct mining of the rock mass. The analysis encompassed the operation of a longwall shearer along with an armoured face conveyor and a main haulage conveyor. The registered results of the operating parameters of these machines served as the basis for determining their availability and, subsequently, for identifying their unscheduled downtimes. On the other hand, the system for registering the causes of downtimes, which has been developed and applied in the case at hand (Brodny et al., 2017; Stecuła et al., 2018), was used to determine the causes for the machines under analysis.

The results obtained unambiguously indicate that unscheduled downtimes of mining machines represent a significant problem for the maintenance of production continuity and may disrupt the process of production planning (Jonek-Kowalska, 2017a; Jonek-Kowalska and Turek, 2017). During the tests, which spanned over one working week of the longwall system, there were a large number of such downtimes, amounting to approximately half of the ordinary working hours of the machines in question.

These results demonstrate that it is necessary to undertake more decisive measures in order to improve this situation. In the Author's opinion, a considerable part of the problems related to the occurrence of these downtimes stems from inappropriate organisation of work and incomplete knowledge of the employees in this regard. To improve this situation, it seems necessary to enhance the effectiveness of the employee training system. The steps taken in this respect so far has been defined by the employees themselves as unsatisfactory (Palka et al., 2017; Palka, 2017). A change in the philosophical approach to work by mine workers seems to be the right direction of the transformation in the mining industry, which is aimed at improving its viability (Stecuła et al., 2017b).

The paper presents the results of the tests carried out according to the methodology presented in other works (Brodny et al., 2017; Stecuła et al., 2017a; Stecuła et al., 2018). Due to the limitations on the length of this paper, its description has been omitted.

The tests and analyses conducted show that, in order to objectively determine the operating status of machines, it is necessary to make use of automation systems. Such systems offer a reliable method for registering the working parameters of machines, independently of the employees' subjective assessments. Only such data make it possible to carry out a reliable diagnosis, whose results allow for the implementation of improvement measures.

\section{RESEARCH AND RESULTS}

The purpose of the tests whose results have been presented in the paper was to demonstrate the possibilities of using industrial automation systems for the analysis and assessment of the operating status of selected mining machines. Particular emphasis was placed on determining the impact of unscheduled downtimes in the operation of these machines on their availability. Moreover, the time structure of these downtimes was identified and, based on the data possessed, the causes of some of the registered downtimes were determined. The tests encompassed three machines comprising the automated longwall system, including a longwall shearer along with an armoured face conveyor and a main haulage conveyor. The analysis was based on the data registered by industrial automation systems. While determining the downtimes and availability of the machines, account was taken of the time courses of the currents consumed by these machines and the advance speeds of the longwall shearer. 
Figure 1 presents the time courses of the current consumed by the right cutting drum and advance speeds of the longwall shearer. The time courses encompassed approximately 10 working hours of the shearer (over 583 minutes).

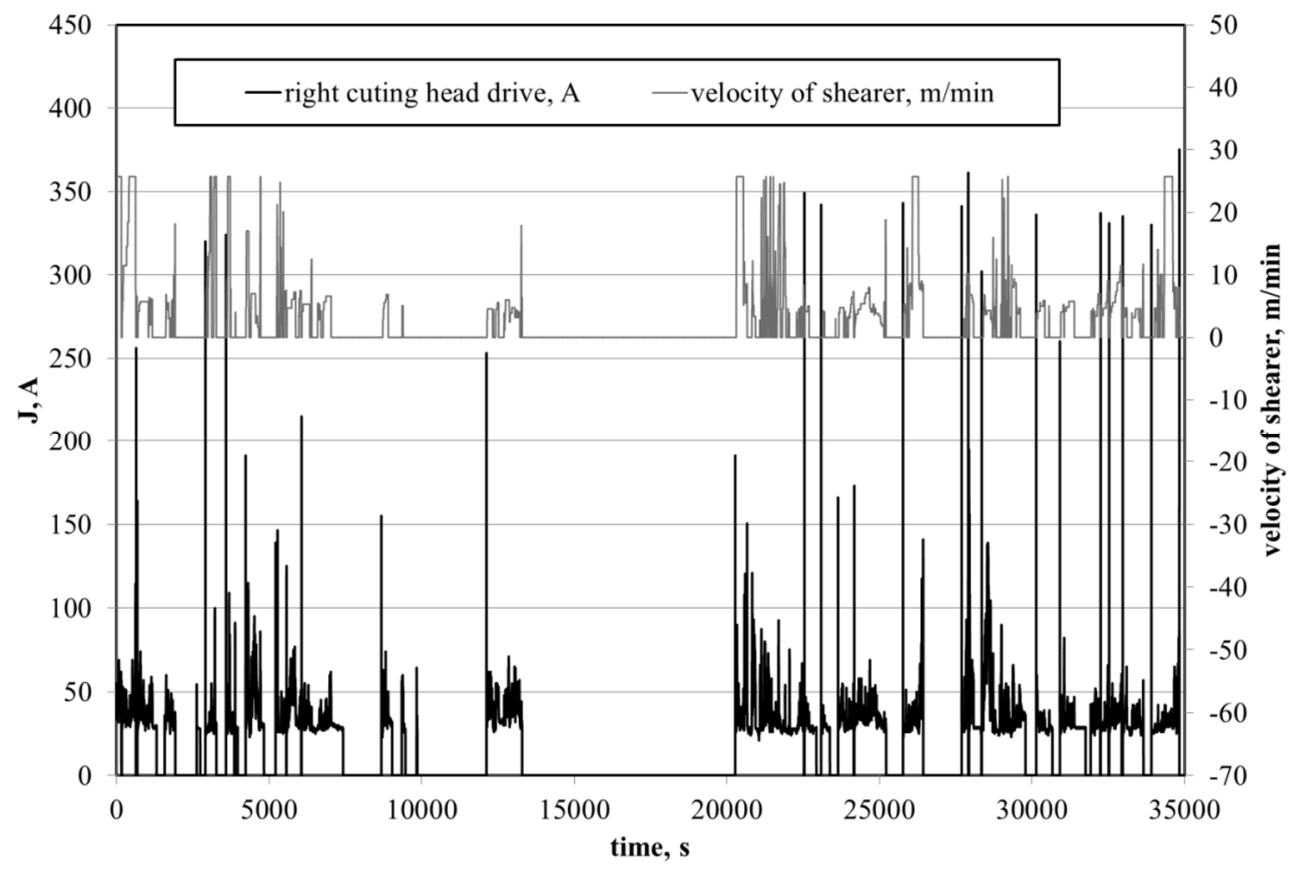

Fig. 1. The time courses of the current consumed by the right cutting drum and advance speeds of the longwall shearer

A similar analysis was conducted for the armoured face conveyor and the main haulage conveyor. In this case, the registration encompassed the time courses of the currents in the main and ancillary motors of the armoured face conveyor and the motor of the main haulage conveyor. These courses for the operating time of these machines equal to approx. 167 minutes have been presented in Figure 2.

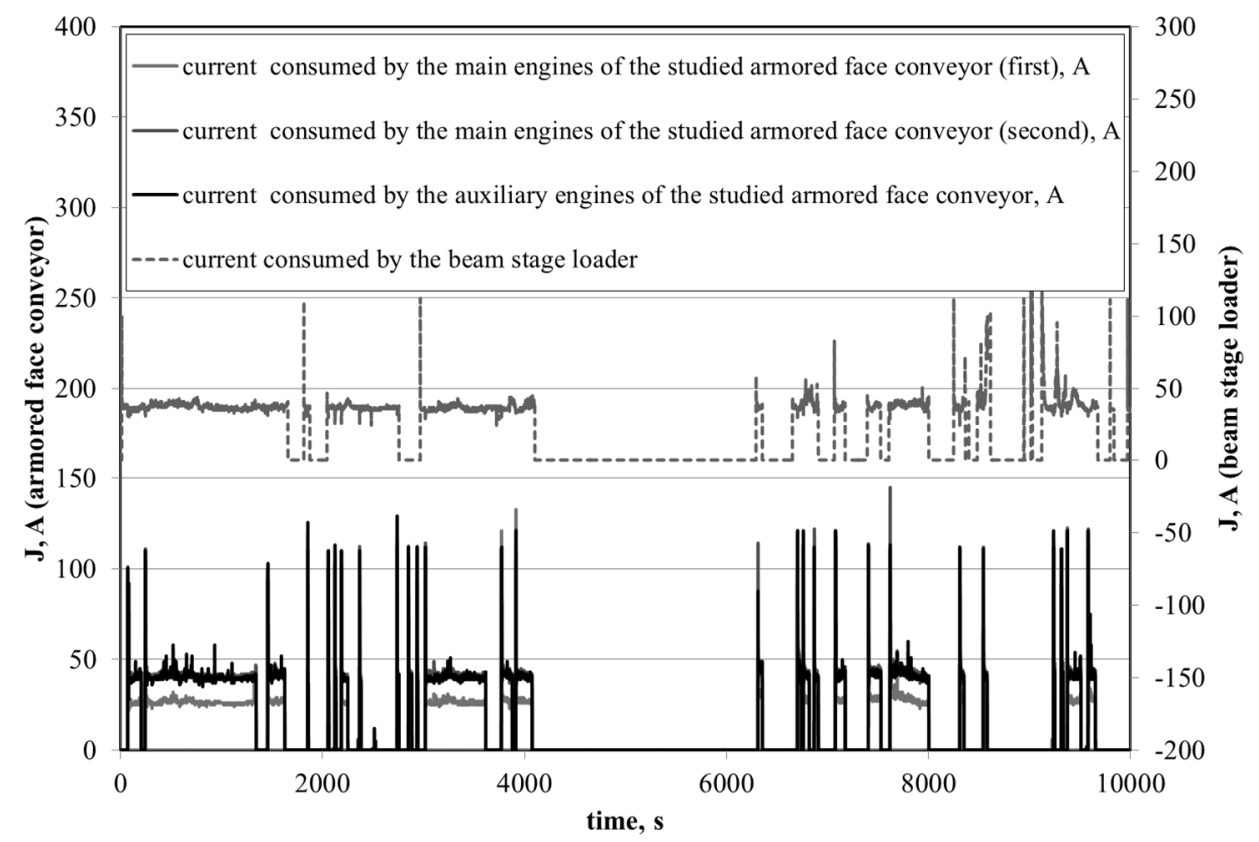

Fig. 2. The time courses of the currents in the main and ancillary motors of the armoured face conveyor and the motor of the main haulage conveyor 
The courses registered served as the basis for determining the availability of the machines under analysis and defining the time structure of the registered downtimes. The analyses were conducted for one working week of the longwall system, encompassing 15 working shifts (i.e. 5,400 minutes of ordinary working time).

Figure 3 shows the availability indicators determined for the machines under analysis for the particular working shifts. They have been defined as the ratio of their actual working hours to the ordinary working time. Moreover, the average value of availability was determined for all the machines under analysis and the results have been additionally summarised in Table 1.

Table 2

The values of availability indicators

\begin{tabular}{|c|c|c|c|}
\hline Machine & $\begin{array}{c}\text { Average values of } \\
\text { availability indicator, \% }\end{array}$ & $\begin{array}{c}\text { Maximum values of } \\
\text { availability indicator, \% }\end{array}$ & $\begin{array}{c}\text { Minimum values of } \\
\text { availability indicator, \% }\end{array}$ \\
\hline The longwall shearer & $49.9 \pm 3.8$ & 55.4 & 44.6 \\
\hline $\begin{array}{c}\text { Armoured face } \\
\text { conveyor }\end{array}$ & $54.1 \pm 4.3$ & 62.8 & 46.7 \\
\hline $\begin{array}{c}\text { Beam stage loader } \\
\text { The entire set of } \\
\text { machines }\end{array}$ & $57.8 \pm 4.4$ & 66.3 & 51.7 \\
\hline
\end{tabular}

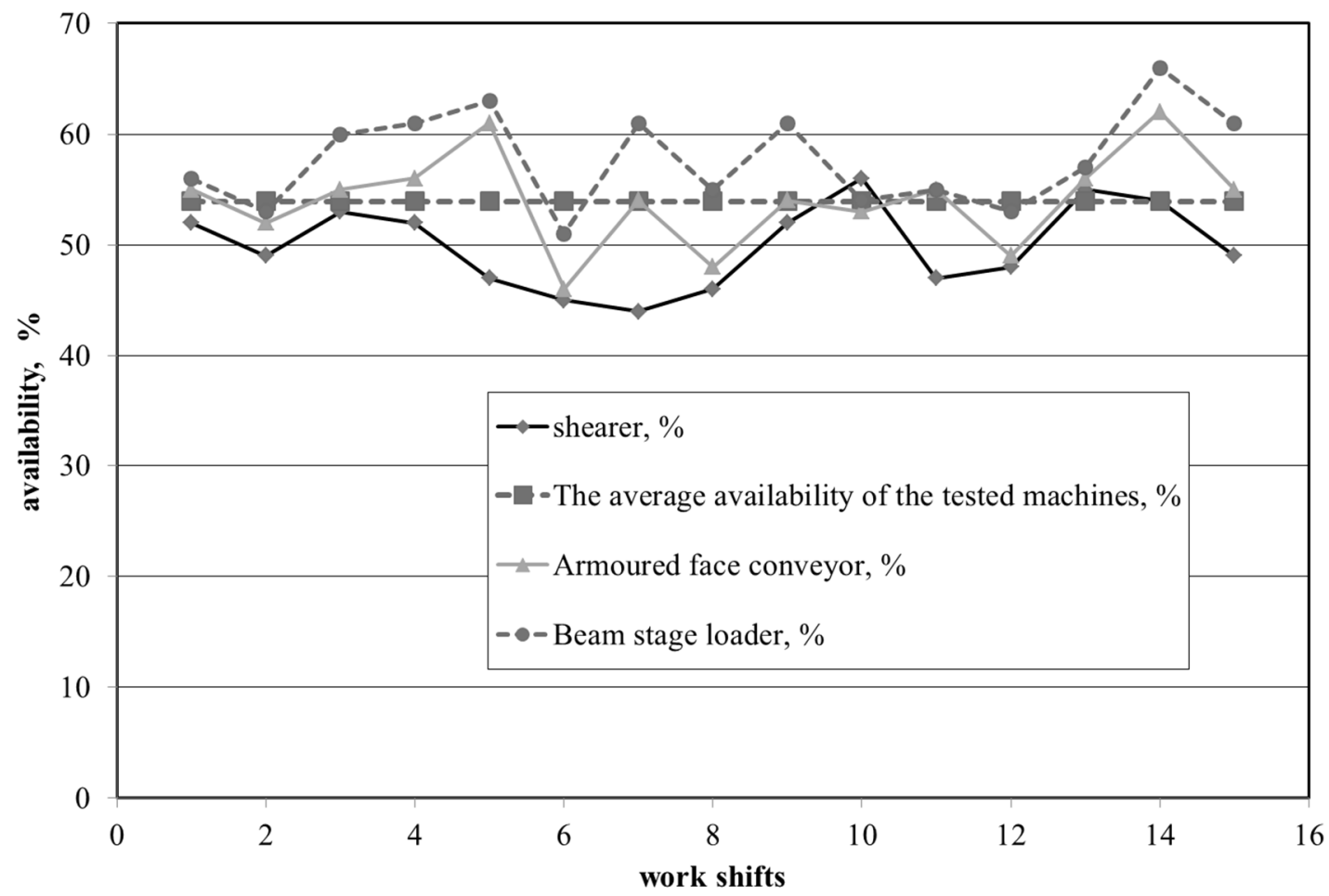

Fig. 3. The availability indicators determined for the machines under analysis for the particular working shifts

The results also served as the basis for analysing the time structure of the unscheduled downtimes registered in the machines' operation for the period under analysis. The results obtained for the longwall shearer have been presented in Figure 4. The application of the pilot system for registering the causes of downtimes made it possible to identify a substantial part of such causes. In this respect, it was possible to identify the causes of approximately $56 \%$ of unscheduled downtimes in the operation of the longwall shearer in the period under analysis. The causes of these downtimes have been summarised in Figure 5. 


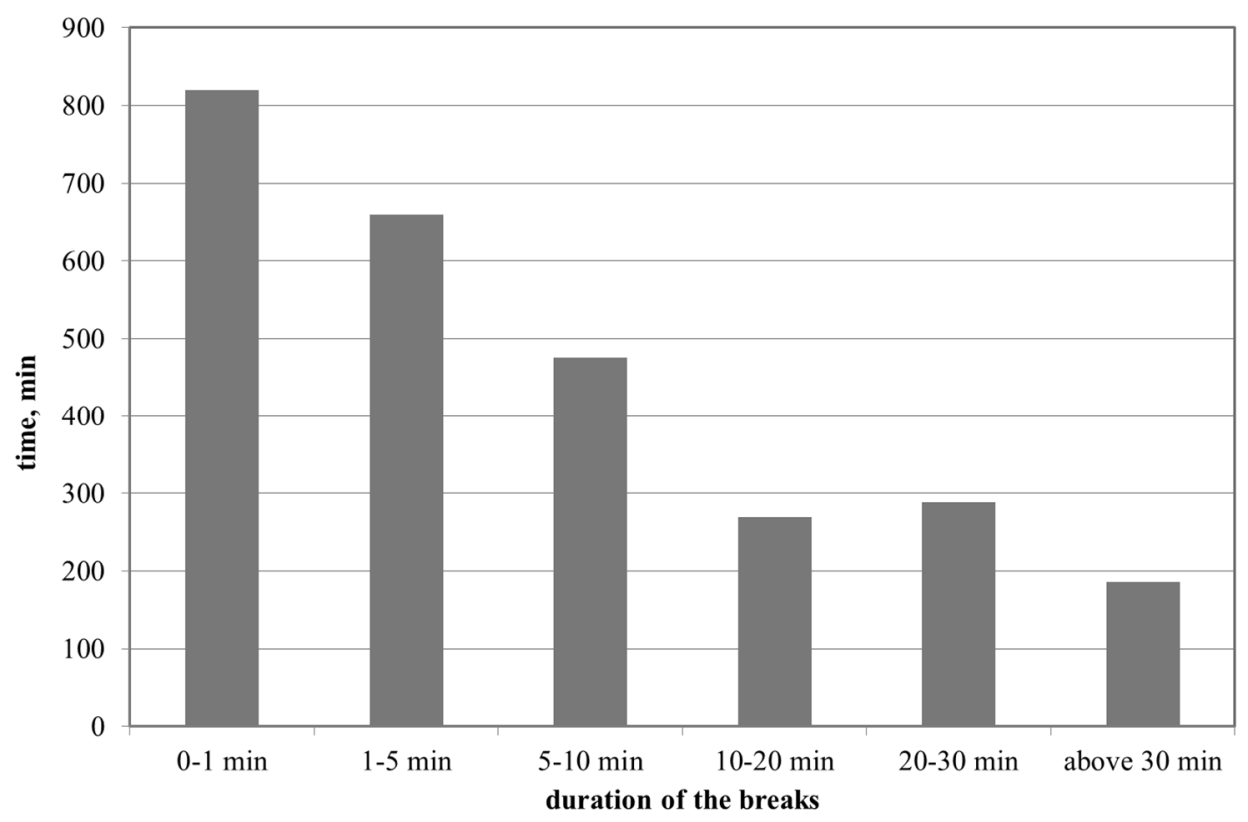

Fig. 4. The availability indicators determined for the machines under analysis for the particular working shifts

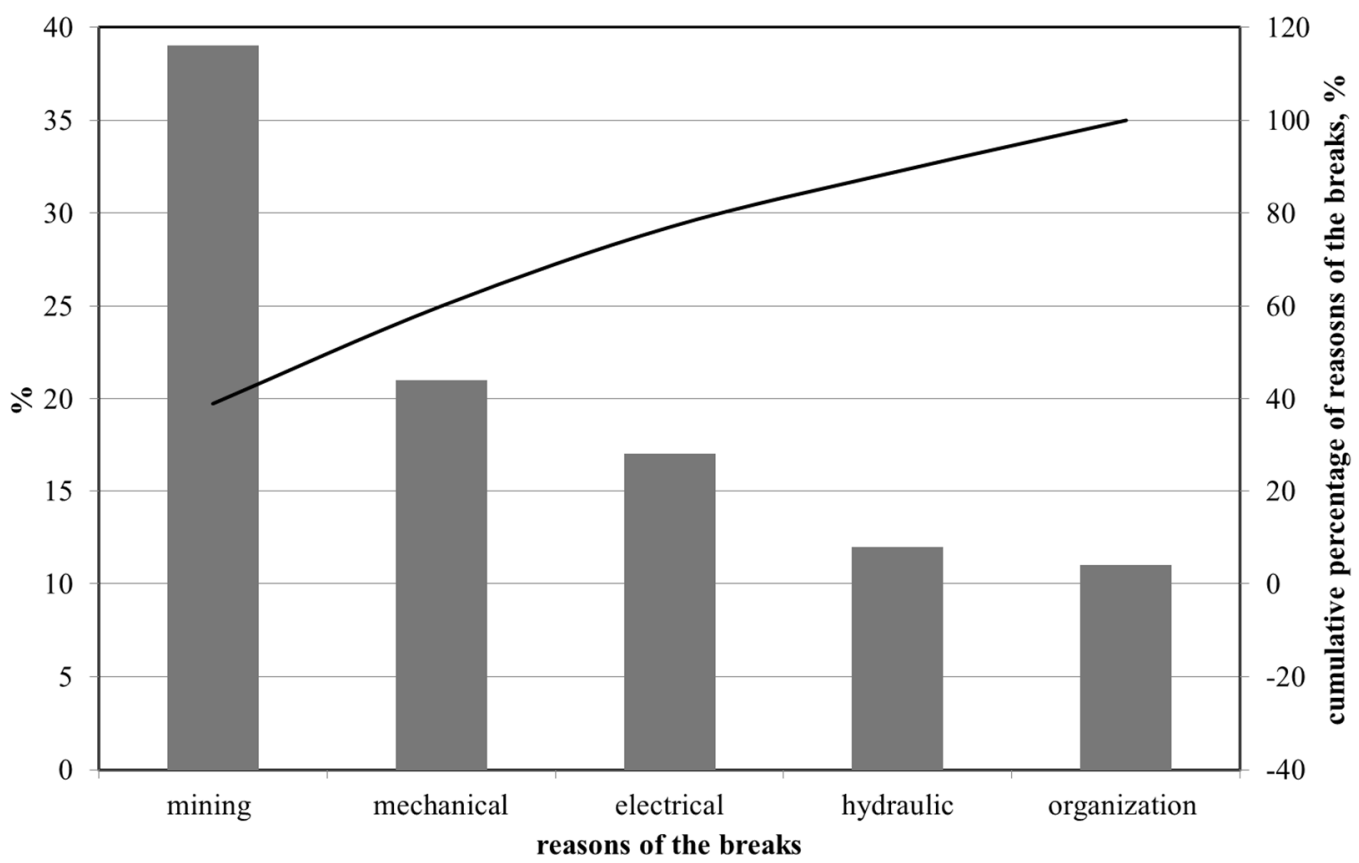

Fig. 5. The availability indicators determined for the machines under analysis for the particular working shifts

\section{CONCLUSION}

The issues presented in the paper are of crucial importance for the process of hard coal production. This is because the effectiveness of this process depends on the utilisation degree of the technical resources owned by mining enterprises. These resources are mainly comprised of all types of equipment, including machines used in mining exploitation. The method presented in the paper for analysing the operation of machines involved in mining exploitation makes it possible to determine a number of interesting working parameters. The example at hand concentrates on a longwall shearer as well as an armoured face conveyor and a main haulage conveyor. From the perspective of work continuity in the mine, these 
machines are extremely important. This is because their reliability and effectiveness determine the efficacy of the entire exploitation process. The results presented are based on the data obtained from the industrial automation system. This makes it possible to objectively determine a number of operating parameters of the machines under analysis. This, in turn, represents the basis for a more in-depth analysis of the production process and allows for more reliable identification of the problems present in this process.

The example at hand focuses on the determination of availability for the machines under examination and on the identification of the structure and causes of the unscheduled downtimes occurring in the production process. The results obtained clearly demonstrate that the machines in question were underused in the period under analysis. The availability values determined were around $50 \%$ of their ordinary working hours. The average for all the machines analysed amounted to less than $54 \%$. Even considering the specific conditions in which mining exploitation takes place, the values obtained are very low. It should also be stressed that no critical events were recorded during the period of analysis, which could have significantly disrupt the production process.

The analysis of the downtimes registered in the operation of the shearer indicates that the great majority of such downtimes constitute disruptions of a short duration. More than half of the downtime duration included interruptions not longer than 5 minutes. In this case, it seems reasonable to verify the causes and validity of these downtimes.

The tests in this field do not fully clarify such causes. The registration system used for this purpose mainly made it possible to identify the causes of downtimes lasting more than 5 minutes. Nevertheless, the analysis of the results indicates that the primary cause is mining problems related to the rock mass. There were also a dozen of downtimes in the operation of the shearer caused by the organisational factor. It can be assumed that these causes should be examined in the first place and, whenever possible, resolved.

The present paper indicates the necessity of broader application of IT tools and elements of industrial automation for analysing the process of mining production. At the same time, a number of areas were identified where these tools could be used without major expenditures. The analysis of literature clearly indicates that practical application of these machines in the mining sector is becoming increasingly common today (Brodny et al., 2017; Stecuła et al., 2018; Brychczy, 2007; Brychczy, 2011). The results obtained should provide an essential source of information for the maintenance department and the management of mines.

\section{ACKNOWLEDGEMENTS}

This article is the result of the research project No. PBS3/B6/25/2015 „Application of the Overall Equipment Effectiveness method to improve the effectiveness of the mechanized longwall systems work in the coal exploitation process" realized in 2015-2018, financed by NCBiR.

\section{REFERENCES}

Brodny, J. and Tutak, M. (2016). Determination of the zone endangered by methane explosion in goaf with caving of operating longwalls. SGEM2016 Conference Proceedings, Book1 Vol. 2, 299-306 pp. DOI: 10.5593/SGEM2016/B12/S03.039.

Brodny, J., Tutak, M. and Michalak, M. (2017). The use of the TGŚP module as a database to identify breaks in the work of mining machinery. BDAS 2017, Beyond Databases, Architectures and Structures. Towards Efficient Solutions for Data Analysis and Knowledge Representation. pp.441452. DOI: 10.1007/978-3-319-58274-0 35.

Brzychczy, E. (2007). Modelling and optimisation method of mining works in hard coal mine with an application of stochastic networks. Part 4. Optimization procedurę. Mineral Resources Management Volume: 23 Issue: 1 Pages: 121-128.

Brzychczy, E. (2011). The planning optimization system for underground hard coal mines. Archives Of Mining Sciences, Volume: 56 Issue: 2 Pages: 161-178. 
Jonek-Kowalska, I. (2017a). Market risk in the hard coal mining industry in Poland in the context of the mining production planning. Proceedings of the Second International Conference on Economic and Business Management. FEBM 2017, Eds. Piman Limpaphayom, Gordon Huang. Advances in Economics, Business and Management Research, vol. 33 Atlantis Press, p. 770-776.

Jonek-Kowalska, I. and Turek, M. (2017b). Dependence of total production costs on production and infrastructure parameters in the Polish hard coal mining industry. Energies vol. 10 iss. 10, art. no. 1480 pp. $1-22$,

Palka, D. (2017). The role and importance of training for improving the safety and awareness of the technical staff in the mining plant. CBU International Conference Proceedings 2017: Innovations in Science and Education, Vol. 5, Prague 2017, p. 1195-1198. DOI: 10.12955/cbup.v5.1095.

Palka, D., Brodny, J. and Stecula, K. (2017). Modern means of production and the staff awareness of the technical in the plant of the mining industry. CBU International Conference Proceedings 2017: Innovations in Science and Education, Vol. 5, Prague 2017, p. 1190-1194. DOI: 10.12955/cbup.v5.1094.

Secuła, K., Tutak, M. and Brodny, J. (2017b). Application of chosen elements from japanese production and maintenance management philosophies in polish coal mines. SGEM 2017. Vol. 17, issue 13. pp. 93-100. DOI: doi.org/10.5593/sgem2017/13.

Stecuła, K., Brodny, J. and Palka, D. (2017a). Analysis of reasons for unplanned stoppages of ma-chines in the example of the longwall shearer. CBU International Conference Proceedings 2017: Innovations in Science and Education, Vol. 5, Prague 2017, p. 1210-1214. DOI: 10.12955/cbup.v5.1098

Stecuła, K., Brodny, J. and Tutak, M. (2018). Use of intelligent informatics module for registration and assessment of causes of breaks in selected mining machines. Intelligent Systems in Production Engineering and Maintenance ISPEM 2017, Advances in Intelligent Systems and Computing 637, pp.74-84.DOI 10.1007/978-3-319-64465-3_8.

Tutak, M. (2017a). Analysis of varying levels of methane emissions from coal mines in Poland. SGEM2017 Vienna GREEN Conference Proceedings, Vol. 17, Issue 43, 301-308 pp; DOI: 10.5593/sgem2017H/43/S19.038.

Tutak, M. (2017b). Assessment of hydrodynamics of gas flow through the porous rock structures. 17th International Multidisciplinary Scientific GeoConference SGEM 2017, SGEM2017 Vienna GREEN Conference Proceedings, Vol. 17, Issue 15, 53-60 pp; DOI: 10.5593/sgem2017H/15/S06.007.

Tutak, M. and Brodny, J. (2017b). Determination of Particular Endogenous Fires Hazard Zones in Goaf with Caving of Longwall. IOP Conf. Series: Earth and Environmental Science 95, 042026 doi:10.1088/1755-1315/95/4/042026. 